\title{
EXPERIMENTAL AND NUMERICAL ANALYSIS OF THE DEEP DRAWING PROCESS USING OPTICAL MEASURING SYSTEM
}

\begin{abstract}
In this paper optimization of the deep drawing process with using a modern photogrammetric measurement system is discussed. The results obtained from optical measuring are compared with the results of a numerical simulation. The numerical simulation of this process was performed using two commercial FEM codes, which use different time integration schemes. Various results are illustrated in the details, compared and discussed. Optimization of the deep drawing process can reduce the amount of product defects, production cost and can improve the quality of products.
\end{abstract}

Keywords: deep drawing, numerical simulation, photogrammetric measurement system

\section{Introduction}

The deep drawing process is nowadays frequently used manufacturing technology in the industrial sphere. Many factors influence on a procedure of the forming process. These factors include for example the holding force $[1,2]$. In order to optimize this process, numbers of tests have to be done. Their results may predict problematic or critical areas of the final product. Due to this in the industrial practice, numerical simulations are often used and they are based on finite element method (FEM) analysis and different time integration schemes. The most known integration schemes are the static implicit and the dynamic explicit. There are many publications which claim that only the dynamic explicit time integration scheme is accurate [3-5] or only the static implicit scheme is accurate enough [6-8]. In explicit strategy the current time step is solved once, resulting from previous time step. Based on required accuracy a mesh is locally redefined and changed. The problem is not solved again, and the solving process is not iterated. The method is convenient for tasks where the solution does not change in time [9]. Implicit strategy is in every time step starting from the previous time step and the mesh is generated using local refinement due to requiring 
accuracy of the problem, which is calculated on the current mesh. This solving process is iterated until the estimated error is between the bounds of an interval and requiring precision. If the time step between a new iteration is not too large, the time of the solving process is usually very small [9]. The results of the numerical simulation may be compared with the ARGUS photogrammetric measuring system. The ARGUS is the contactless measuring system that on the basis of optical scanning allows predicting critical areas which take place during the forming process. On the sheet metal, a grid of circle points is etched before forming. The size of these points is between 1 and $6 \mathrm{~mm}$. The grid is deformed at the same time as the sheet metal is deformed. The grid of circle points is deformed by the influence of direction and intensity of stresses, and its shape is changed. The measurement depends on the photogrammetric principle where the surface of a stamped part is scanned using a CCD camera in high resolution. Pictures are taken from different angles, and 3D coordinates of grid points are computed using image processing. Distances between points of the grid are defined by lateral distortion. On the basis of law of volume preservation distributions of major and minor strains, thickness reduction or critical areas of the drawn part are computed. Based on the defined material, forming limit diagram (FLD) is plotted [10]. After all points are recognized, the 3D model of the drawn part is rendered, and analysis of strains, stresses, the thickness over a section can be performed. There are several studies which dealt with the similar problems $[11,12]$. The material of a blank defined in the numerical simulation was in the case of a yield function approximated using Hill 48 yield function which is defined by the following law [13, 14]:

$$
\begin{aligned}
\varphi\left(\sigma_{i j}\right)= & F\left(\sigma_{22}-\sigma_{33}\right)^{2}+G\left(\sigma_{33}-\sigma_{11}\right)^{2}+H\left(\sigma_{11}-\sigma_{22}\right)^{2}+ \\
& +2 L \sigma_{23}^{2}+2 M \sigma_{31}^{2}+2 N \sigma_{12}^{2}-\bar{\sigma}^{2}=0
\end{aligned}
$$

where: $\Phi\left(\sigma_{i j}\right)$ - stress components with respect to the coordinate system,

$F, G, H, L, M, N$ - Hill's anisotropic parameters, which can be expressed by a normal anisotropy,

$\sigma_{22}, \sigma_{33}, \sigma_{11}, \sigma_{23}, \sigma_{31}, \sigma_{12}$ - plane stresses; suffix 1 is parallel to the rolling direction, 2 is parallel to the transverse direction,

$\bar{\sigma}-$ scaling factor.

$$
F=\frac{r_{0}}{r_{90}\left(r_{0}+1\right)}, G=\frac{1}{r_{0}+1}, H=\frac{r_{0}}{r_{0}+1}, N=\frac{\left(r_{0}+r_{90}\right)\left(1+2 r_{45}\right)}{2 r_{90}\left(1+r_{0}\right)}
$$


where: $r_{0}, r_{45}, r_{90}$ - values of the normal anisotropy measured in directions $0^{\circ}$, $45^{\circ}$ and $90^{\circ}$ respectively to the rolling direction,

$L, M$ - coefficients which are equal to the $N$.

A hardening curve was defined by values obtained experimentally and subsequently approximated with the Hockett-Sherby material model [15].

\section{Objectives and approach}

The aim of the experiment was to carry out the simulation of the deep drawing process in the explicit and implicit commercial software and then the results are compared with the real shape of a target product measured using the ARGUS optical measuring system. Mechanical properties of the mild steel DC05 are shown in the Table 1 and the target shape and the picture taken from the ARGUS measuring process are shown in the Fig. 1. The thickness of the blank was $0.8 \mathrm{~mm}$.

Table 1. Mechanical properties of the mild steel DC05

\begin{tabular}{|c|c|c|c|c|c|c|}
\hline $\begin{array}{c}\text { Specimen } \\
\text { orientation }\end{array}$ & $\begin{array}{c}\boldsymbol{R}_{\boldsymbol{p} \mathbf{0 . 2}} \\
{[\mathbf{M P a}]}\end{array}$ & $\begin{array}{c}\boldsymbol{R}_{\boldsymbol{m}} \\
{[\mathbf{M P a}]}\end{array}$ & $\begin{array}{c}\boldsymbol{A}_{\mathbf{8 0}} \\
{[\mathbf{\%}]}\end{array}$ & $\boldsymbol{n}$ & $\begin{array}{c}\boldsymbol{C} \\
{[\mathbf{M P a}]}\end{array}$ & $\boldsymbol{r}$ \\
\hline $0^{\circ}$ & 145 & 292 & 50.8 & & & \\
\hline $45^{\circ}$ & 151 & 298 & 47.9 & \multirow{2}{*}{0.254} & 538.5 & 1.888 \\
\hline $90^{\circ}$ & 149 & 290 & 48.0 & & & 2.464 \\
\hline
\end{tabular}

where: $R_{p 0.2}$ - yield stress, $R_{m}$ - ultimate strength, $A_{80}$ - total elongation,

$n-$ strain hardening exponent, $C$ - strain coefficient, $r$ - normal anisotropy

a)

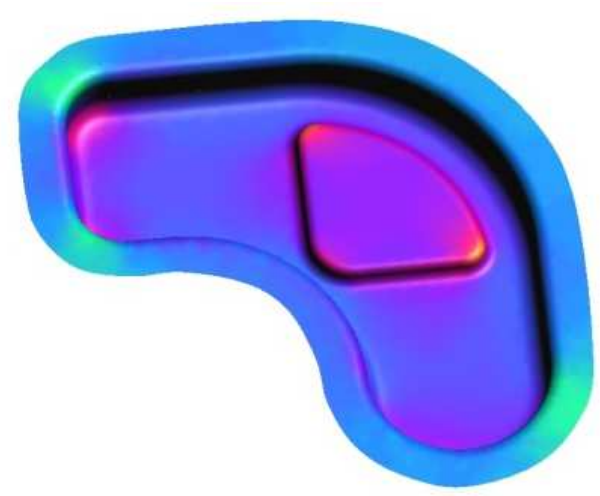

b)

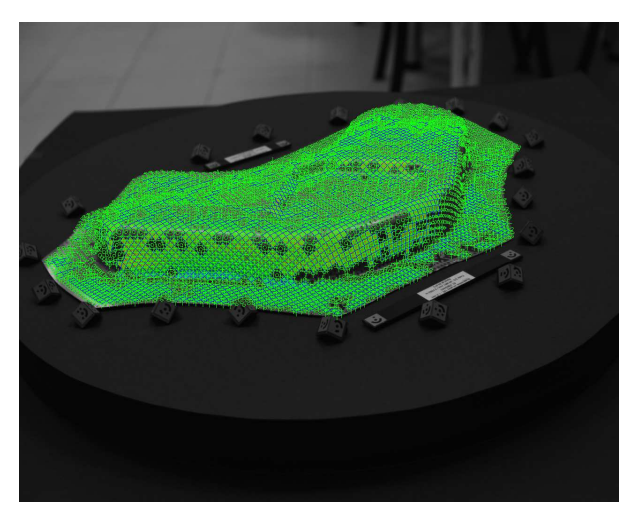

Fig. 1. Shape of the drawn part in FEM code (a) and measured in ARGUS system (b) 
The punch, die and blankholder shown in the Fig. 2 were modeled in the CAD software and exported to each of FEM code. Simulation was performed in the Autoform and PAM-STAMP code. A shell element type with a different number of integration points was used. In the case of the explicit code the number of integration points was 5 , and 11 in case of the implicit code. The implicit code uses a triangular mesh type with angles of $30^{\circ}$, and explicit code uses a rectangular mesh type with the size of $9.7 \mathrm{~mm}$. The size of the element after refinement was equal to $1.2 \mathrm{~mm}$. Stages defined in both FEM codes are shown in the Table 2.

Table 2. Stages defined in the implicit and explicit code

\begin{tabular}{|c|c|c|c|}
\hline No & Stage/Code & Implicit & Explicit \\
\hline 1 & Positioning & yes & yes \\
\hline 2 & Holding & yes & yes \\
\hline 3 & Drawing & yes & yes \\
\hline 4 & Springback & yes & yes \\
\hline 5 & Cutting & yes & no \\
\hline
\end{tabular}

The measurement of deformations, thickness reduction and 3D shape by the ARGUS optical measuring system was performed in the way as it was described in the previous chapter. Distances between centers of circles on the grid etched on the sheet were $1.5 \mathrm{~mm}$. The results of the numerical simulation and the ARGUS measuring system will be described in the following chapter.

a)

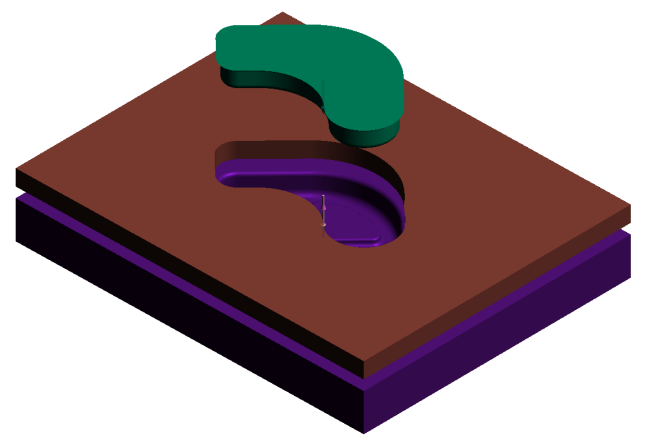

b)

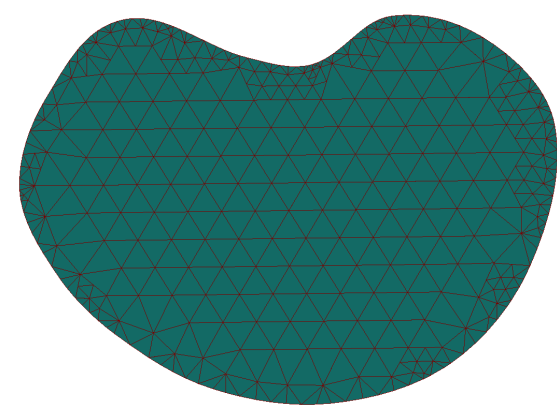

Fig. 2. Assembly of tools in the FEM code (a) and the triangular refinement of the blank (b)

\section{Results of experiment}

In order to compare differences between the results obtained from the ARGUS measuring system and numerical simulation, SVIEW software was 
used. This comparison is necessary for interconnection of the model obtained from the FEM simulation and the model obtained from the ARGUS measuring system. All kind of inaccuracies defined in the numerical simulation can be found exactly by this comparison. The value of deviation between models is connected with the error of material model definition, the shape of tools and technological parameters defined in the numerical simulation. The deviation between models is showed in the Fig. 3 .

a)

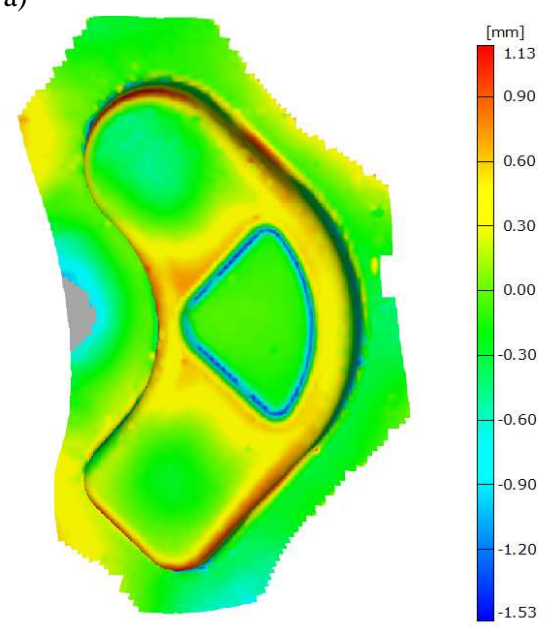

b)

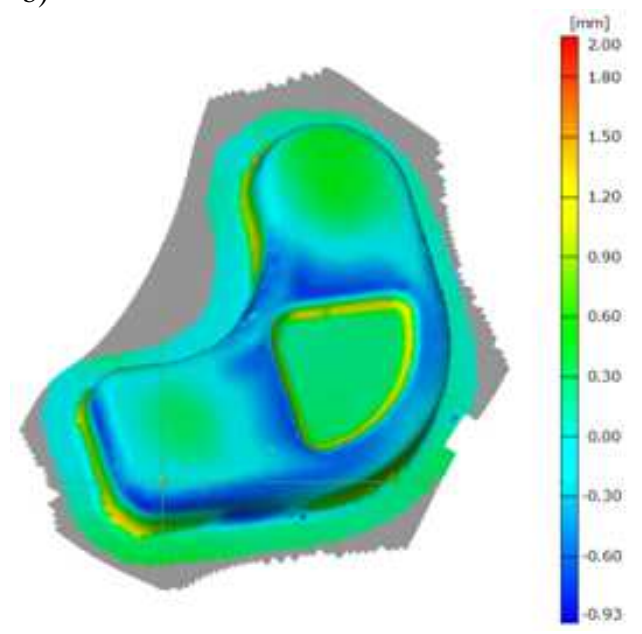

Fig. 3. Deviation of geometry of models obtained from ARGUS used explicit (a) and explicit (b) code

Hence all parameters had the same value in the case of using the explicit and implicit codes, so comparison of these solvers could be discussed. It can be seen in the Fig. 3 that both codes showed similar deviation between models, but greater geometry deviation was observed in the case of implicit solver $-2.93 \mathrm{~mm}$ in the absolute value. The absolute value of deviation when the explicit solver was used is $2.66 \mathrm{~mm}$.

The FLD diagram of the drawn part has a key role in the assessment of the technical process suitability. The FLD diagrams exported from FEM code and the ARGUS measuring system are showed in the Fig. 4 and 5. As it can be seen, neither in FEM code, nor in the ARGUS measuring system, none point is near or over forming limit curve. The FLD diagrams were exported for the bottom membrane of the part, because by using the ARGUS measuring system it is impossible to measure deformations or to obtain FLD in neutral membrane.

Strain path of FLD is more suitable in the case of the explicit integration scheme as shown in the Fig. 5b. In the case of the ARGUS measuring system 
some points in the area over $60 \%$ of major strain are visible, these points have not appeared in the FLD obtained from FEM codes.

As it was mentioned, in the ARGUS measuring system a course of thickness reduction over section can be plotted. To analyze the accuracy of FEM code in comparison to ARGUS results, analysis of the thickness reduction was performed. The section through the drawn part was showed in the Fig. 6. The reason for selecting this section was that a few critical areas are near this section. This section was defined in both FEM models and the results were compared.

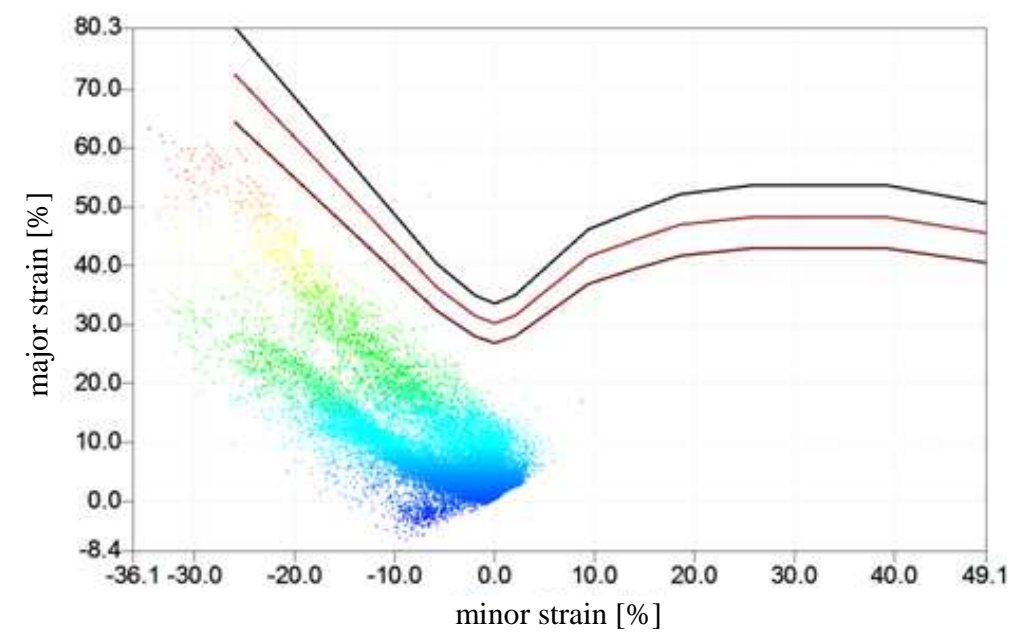

Fig. 4. FLD diagram obtained from ARGUS optical measuring system

Distribution of thickness reduction over section is showed in the Fig. 7. In this picture distribution of thickness reduction obtained from the ARGUS measuring system and FEM simulations are presented. For better understanding and orientation, section over part is represented by broken line. As it can be seen in the Fig. 7, the ARGUS, and numerical simulations recognized the problematic areas in the same places. The greatest value of thickness reduction is observed in the bottom of the drawn part. On the left radius, both - explicit and implicit codes overestimated the amount of the thickness reduction. On the right side of the drawn part, the thickness reduction was underestimated by the both FEM codes. In this case it is better to overestimate thickness reduction, because this can predict future defect. Smaller differences between numerical results and the ARGUS are observed on the right bottom radius (Fig. 7). The smallest amount of thickness reduction is observed on the bottom of the drawn part. 
a)

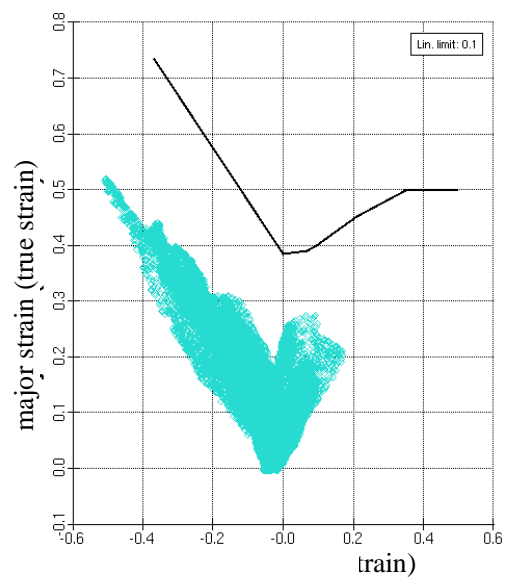

b)

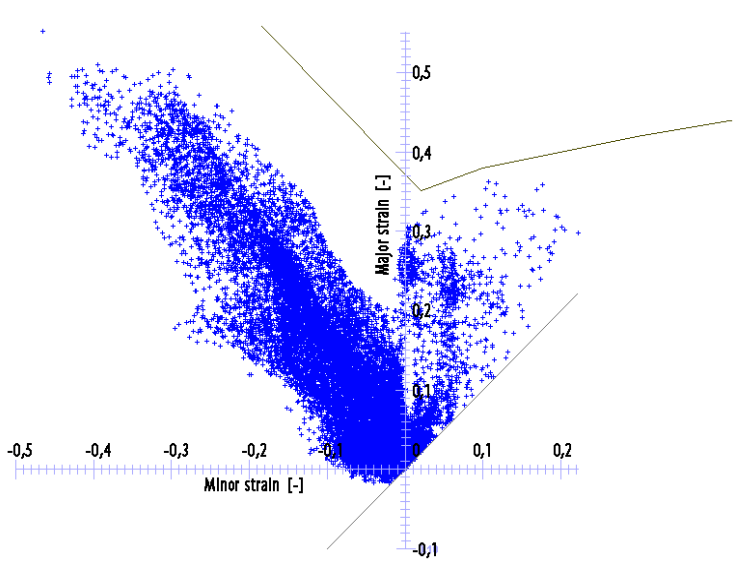

Fig. 5. FLD diagram determined using implicit (a) and explicit (b) solver

Fig. 6. Illustration of section over drawn part
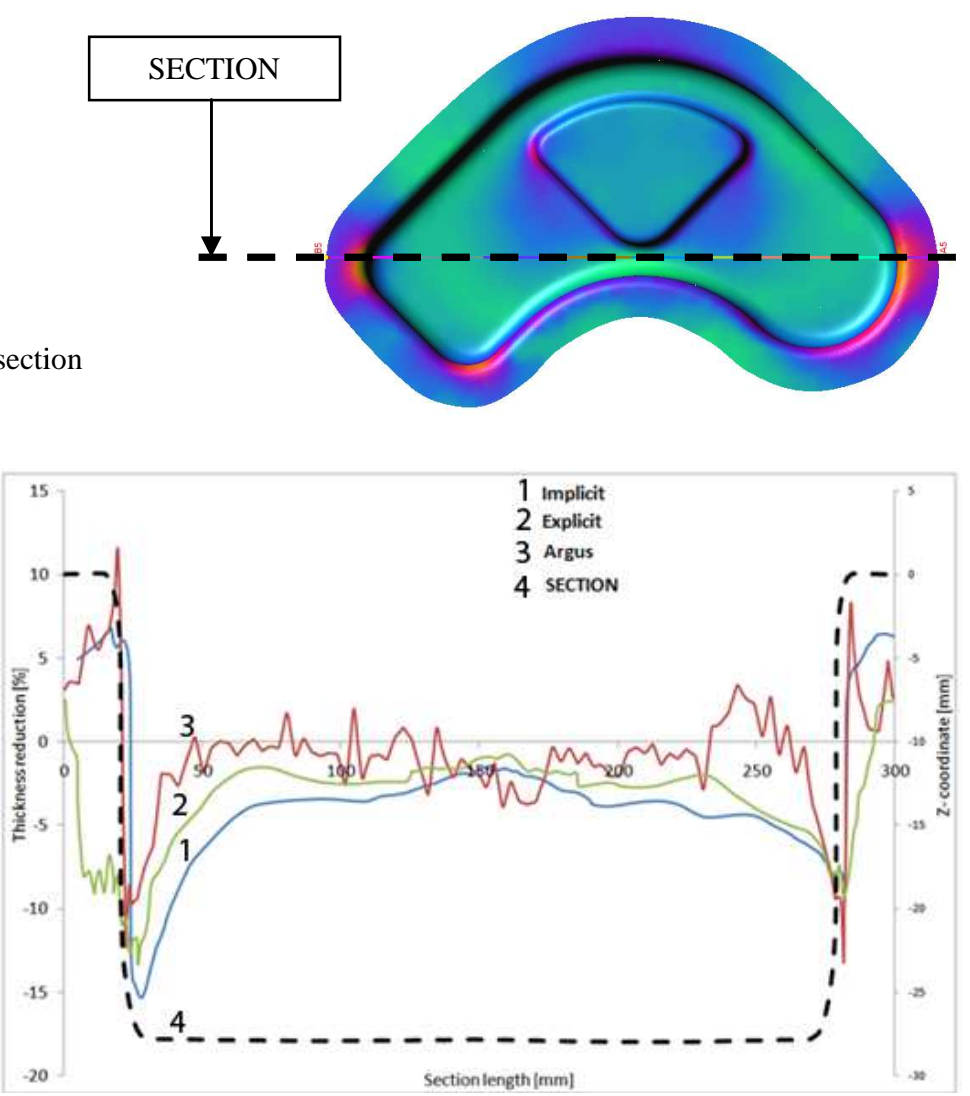

Fig. 7. Illustration of section over drawn part 


\section{Conclusion}

Analyses of the deep drawing process using-the ARGUS optical measuring system were discussed. Simulations were carried out using two different FEM codes and verified with results of experimental measurements. It can be concluded, that both codes had approximately the same results. Using this method it is possible to verify material models used to define blank behavior. It can be concluded that the results of the numerical simulation are accurate enough to predict critical areas of the drawn part. The same critical places of the drawn part were recognized with the ARGUS measuring system and both FEM codes. In the case of the FLD diagram there were no points over the forming limit curve. Considering the fact that implicit code needs less computing time according to explicit code, and the results varied about small values, it can be concluded that the implicit code is more convenient to use. Moreover, the implicit code needs less parameters which have to be defined, and needs less time spending with definition. Using the ARGUS optical measuring system leads to prediction critical areas on the drawn part and to optimization of the whole deep drawing process.

\section{References}

[1] Ahmetoglu M., Altan T.: Deep drawing of round cups using variable blank holder force (BHF), Reoirt Bi, ERC/NSM-S, Engineering Research Centre for Net Shape Manufacturing, Ohio State University, Ohio 1992.

[2] Obermeyer E.J., Majlessi S.A.: A review of recent advances in the application of blank holder force towards improving of the forming limits of sheet metal parts, J. Mat. Proc. Technol., 75 (1998), 222-234.

[3] Lig Y., Tan M.J., Liew K.M.: Springback analysis for sheet forming processes by explicit finite element method in conjunction with the orthogonal regression analysis, Int. J. Solids and Structures, 36 (1999), 4653-4668.

[4] Yang D.Y., Jung D.W., Song I.S., Yoo D.J., Lee J.H.: Comparative investigation into implicit, explicit, and iterative implicit/explicit schemes for the simulation of sheet-metal forming processes, J. Mat. Proc. Technol., 50 (1995), 39-53.

[5] Jung D.W.: Static-explicit finite element method and its application to drawbead process with springback, J. Mat. Proc. Technol., 128, 1-3 (2002), 292-301.

[6] Meinders T. et.al.: A sensitivity analysis on the springback behavior of the unconstrained bending problem, J. Mat. Proc. Technol., 9, 3 (2006), 365-402.

[7] Li K., Geng L., Wagoner R.H.: Simulation of springback: Choice of element, [in:] Advanced technology of plasticity, M. Geiger (ed.), vol. 3, Springer-Verlag, Nuremberg 1999, 2091-2099.

[8] $\mathrm{Hu}$ Y.: Quasi-static finite element algorithms for sheet metal stamping springback simulation, Proc. of 4th Int. Conference and Workshop on Numerical Simulation of 3D Sheet Forming Processes, NUMISHEET 1999, J.C. Gelin and P. Picart (eds.), 71-76. 
[9] Schmidt A., Kunibert G.S.: Design of adaptive finite element software. The finite element toolbox, Springer-Verlag, Bremen 2004.

[10] ARGUS USER GUIDE, http://www.gom.com/.

[11] Frącz W., Stachowicz F., Pieja T.: Aspect of verification and numerical optimization of sheet metal and numerical simulations process using the photogrammetric system, Acta Metallurgica Slovaca, 19 (2013) (in press).

[12] Solfronk P., Sobotka J.: Utilization of forming tool with variable blankholder force for drawing of al alloys, Physics Procedia, 22 (2011), 233-238.

[13] Réche J., Besson J., Sturel T., Lemoine X., Gourgues-Lorenzon A.F.: Analysis of the air-bending test using finite-element simulation: Application to steel sheets, Int. J. Mech. Sci., 57 (2012), 43-53.

[14] Roll K.: Simulation of sheet metal forming - Necessary developments in the future, Int. Conf. NUMISHEET 2008, Interlaken, Switzerland 2008, 3-11.

[15] AUTOFORM user guide, http://www.autoform.com/.

This contribution is the result of projects implementation: Center for research of control of technical, environmental and human risks for permanent development of production and products in mechanical engineering (ITMS: 26220120060) supported by the $R \& D$ Operational Programme funded by the ERDF and VEGA 1/0396/11.

\title{
ANALIZA EKSPERYMENTALNA I NUMERYCZNA PROCESU GŁĘBOKIEGO TŁOCZENIA ZA POMOCĄ OPTYCZNEGO SYSTEMU POMIAROWEGO
}

\begin{abstract}
Streszczenie
Wyniki otrzymane z zastosowaniem optycznego systemu pomiarowego zostały porównane $\mathrm{z}$ wynikami symulacji numerycznych. $\mathrm{W}$ artykule przedstawiono optymalizację procesu głębokiego tłoczenia $\mathrm{z}$ wykorzystaniem nowoczesnego fotogrametrycznego systemu pomiarowego. Symulacja numeryczna tego procesu została wykonana za pomocą dwóch komercyjnych programów MES z użyciem różnych schematów całkowania czasu. Różne wyniki zostały szczegółowo zilustrowane, porównane i omówione. Optymalizacja procesu głębokiego tłoczenia może zmniejszyć liczbę wad wyrobu i koszt produkcji oraz poprawić jakość wyrobów.
\end{abstract}

Słowa kluczowe: głębokie tłoczenie, symulacja numeryczna, fotogrametryczny system pomiarowy

DOI: $10.7862 / \mathrm{rm} .2012 .10$ 